\title{
Traditional versus fast fashion supply chains in the apparel industry: an agent-based simulation approach
}

\author{
Sabrina Backs ${ }^{1}$ D $\cdot$ Hermann Jahnke ${ }^{1}$ - Lars Lüpke ${ }^{1} \cdot$ Mareike Stücken $^{1}$. \\ Christian Stummer ${ }^{1}$
}

Published online: 21 July 2020

(c) The Author(s) 2020

\begin{abstract}
In the past, most companies in the European apparel industry focused on minimizing manufacturing costs in the design of supply chains in conjunction with long-distance shipping from production sites in the Far East and relatively long production cycles. Today, for some market segments, the speed of production cycles is more important than the cost because short throughput time allows the flexibility to adjust to rapidly changing fashion trends in these market segments. Accordingly, choosing the most beneficial supply chain strategy has become an established research topic. However, apparel markets are complex systems. Therefore, attempts to reduce the underlying complexity in order to model these markets have limited existing research to the consideration of only selected aspects of markets (e.g., considering only homogeneous buyers, a single period, a single product, or a single manufacturer in the absence of competition) rather than taking a more comprehensive view. These limitations can be overcome by applying an agent-based simulation approach — an approach that can account for a wider range of factors, including several competing manufacturers utilizing different supply chain strategies, individual consumer preferences and behavior, word-of-mouth communication, normative social influence, and first-hand experience, as well as advertising. In this paper, the capability potential of such agent-based market simulation is demonstrated by investigating two supply chain strategies (fast fashion vs. traditional fashion) with varying product and communication strategies (product attributes and advertising) in several market scenarios.
\end{abstract}

Keywords Agent-based simulation · Supply chain management · Apparel industry · Fast fashion

\section{Introduction}

What is the supply chain strategy of choice for the apparel industry? Over the last two decades, this question has become more and more important for managers of fashion man-

Sabrina Backs

sbacks@uni-bielefeld.de

1 Department of Business Administration and Economics, Bielefeld University, Universitätsstr. 25, 33615 Bielefeld, Germany 
ufacturers as well as for scientists in the field of business administration. The question calls for understanding the differences between the established traditional strategy and the fast fashion strategy.

The traditional strategy (which rose to prominence in the 1960s in Europe) is characterized by sourcing production from low-wage countries, leading to lower labor costs as well as longer transportation times, and thus, to a reduction in the flexibility of the logistical processes. Therefore, in the traditional system, sales forecasts must be made well in advance of the selling season, resulting in rather high demand uncertainty. Usually, large quantities of each item are procured, covering the estimated demand for the full sales period and including sufficient safety stocks. This way, manufacturers attempt to prevent stock-outs so that as many items as possible can be sold during the season, including through end-of-season sales at reduced prices. Overall, the focus of the traditional strategy is on producing standardized clothes at the lowest possible cost.

The fast fashion strategy, in contrast, differentiates between two separate product categories: basic products (e.g., plain t-shirts), which are procured analogously to those in the traditional supply chain strategy, and fashion clothes, which are sourced from producers located closer to the point of sale (mostly in European countries). The latter approach incurs higher labor costs and thus higher production costs, but it also provides increased flexibility due to shorter transportation distances. Consequently, demand forecasts can be made much closer to the selling season and can even be driven by real-time data from the points of sale. This approach, therefore, benefits from lower demand uncertainty. Fashion products are produced in smaller quantities and are offered to the consumer for only a few weeks. Stock-outs are artificially generated to create a sense of scarcity and exclusiveness, and there are no classic end-of-season sales. To summarize, the focus of the fast fashion strategy is on reacting more flexibly to consumer demand and offering more fashionable products. The strategy of fast fashion has come to the fore in recent years driven by increasing globalization and digitization, both responsible for a faster spread of trends. Companies like Zara-the world's largest fast fashion manufacturer and part of the Inditex group—serve as prime examples of the benefits of such a strategy.

When choosing between these two supply chain strategies, several factors must be considered, including the preferences and purchasing behavior of consumers and the nature and strategies of competitors. The interplay of these factors gives rise to a complex market structure, requiring an appropriate tool for the evaluation of such strategies.

Agent-based modeling and simulation allows the consideration of individual consumer preferences, communication from consumers within social networks, and competition between manufacturers. By modeling the behavior of various stakeholders at the micro-level, the emergent behavior of the system (i.e., the market) can be observed at the macro-level. While agent-based simulations are already popular in several fields of business administration, such as in marketing (e.g., Rand et al. 2018; Sonderegger-Wakolbinger and Stummer 2015) or in innovation management (e.g., Kiesling et al. 2012; Negahban and Jeffrey 2018), this approach is novel for investigating supply chain strategies in the apparel industry.

The contribution of this paper is threefold. First, we introduce an agent-based model of an apparel market with consumers and manufacturers as relevant stakeholders who act according to their beliefs and desires as well as interact with others. Second, we demonstrate the strengths of a corresponding market simulation in comparison with an analytic approach by accounting for the heterogeneity of consumers as well as word-of-mouth communication. Third, we study the effectiveness of the two main supply chain strategies (i.e., traditional and fast fashion) in combination with four management measures. 
The remainder of the paper proceeds as follows: we provide an overview of apparel supply chain strategies and discuss the applicability of agent-based simulations in this context in Sect. 2. Section 3 introduces the agent-based model, which is compared to an analytical approach in Sect. 4. In Sect. 5, the model is applied to a fictitious apparel market. The paper concludes in Sect. 6.

\section{Background}

\subsection{Supply chain strategies in the apparel industry}

The topic of choosing a proper supply chain strategy has been addressed in literature reviews, case studies, conceptual papers, quantitative empirical studies, and theoretical model-based approaches (for a literature overview, see Backs et al. 2020). To summarize, in the context of the apparel industry, a number of articles applying qualitative research methods mainly focus on the fields of corporate social responsibility and sustainability (e.g., Li et al. 2014b; Joy et al. 2012; Turker and Altuntas 2014), supply chain management (e.g., Barnes and Lea-Greenwood 2006; Christopher et al. 2004; Ferdows et al. 2004; Tang et al. 2019), and the concept of fast fashion, mostly contrasted with the traditional supply chain strategy (e.g., Caro and Martínez-de-Albéniz 2015; MacCarthy and Jayarathne 2010; Runfola and Guercini 2013). The focus of quantitative empirical studies has mostly been on consumer behavior in the context of apparel supply chain strategies (e.g., Byun and Sternquist 2008; Choi et al. 2010; Morgan and Birtwistle 2009). Previous papers utilizing theoretical models have mainly focused on communication via contracts between different supply chain members (e.g., Li et al. 2014a; Wang et al. 2013) and supply chain management (e.g., Cachon and Swinney 2011; Caro and Gallien 2007, 2010). In an attempt to reduce complexity and dynamic of interaction between market participants, most authors focus on a one-dimensional analysis of the apparel supply chain, thus ignoring a number of other aspects of importance.

\subsection{Prior work by Cachon and Swinney (2011)}

A particularly noteworthy and prominently published analytical approach for studying supply chain management in the apparel industry has been introduced by Cachon and Swinney (2011), who compare four systems - a traditional system, a quick response system, an enhanced design system, and a fast fashion system. These four systems have different implications for the consumer's strategic purchasing behavior. Following Cachon and Swinney, this behavior consists of an intentional delay in purchasing an item while it is offered at the full price with the purpose to buy it during an end-of-season clearance at a lower price.

In the traditional system, lead times are assumed to be long and product design is standardized. Therefore, the firm must design the product and choose inventory levels well before the selling season. Quick response, as defined by Cachon and Swinney (2011), differs from the traditional system in that the firm can procure inventory at two time instances-first, a long time before the selling season begins, as in the traditional system, and second, after receiving a forecast update closer to the beginning of the selling season. This forecast is assumed to be perfectly informative but ordering the second time comes with additional production costs. The product design remains standardized. In the enhanced design system, production lead times are long, but the design of the products gets improved, resulting in greater product value to consumers as well as additional costs for each produced unit. In the fast fashion system, 
finally, the characteristics of quick response and enhanced design are combined so that a second inventory decision is made using better information and transferring higher product value to consumers via the enhanced design. Both measures result in additional costs, but fast fashion entails higher additional costs than these separated systems.

Cachon and Swinney (2011) assume that a firm sells a single product over a finite season. Prior to the selling season, the firm chooses its inventory level and selling price to maximize its expected profit. Consumers decide whether to buy at the full price or wait for a potential clearance sale. The consumers are assumed to be homogeneous in their needs and preferences so that they ultimately all expect the same consumption value for a given product. Owing to the homogeneity, they either all purchase early or all wait for the clearance period. As profits for the four systems under investigation are difficult to determine analytically, Cachon and Swinney resort to a numerical study with, as stated by the authors, realistic scenarios from the fashion apparel industry. Based on the outcomes for several thousand parameter combinations, they concluded that fast fashion is the strategy of choice with respect to profitability in roughly three quarters of these instances.

An obvious limitation of their approach is the assumption of homogeneous consumersthis implies that consumers always attribute the same value to a product and only increase that value to the same extent in the case of an enhanced design, and that all consumers behave strategically in the same way. A second limitation relates to the assumed type of marketonly a single company is considered that only offers a single product. Furthermore, word of mouth and normative social influence are not considered in this approach. Apparently, these assumptions are necessary to make the game-theoretic approach tractable.

\subsection{Suitability of an agent-based simulation approach}

Agent-based simulation is well-suited to overcoming these limitations. Hence, it is useful for modeling the apparel market with its heterogeneous consumers and their individual preferences for products, as well as different competing manufacturers following different supply chain strategies. In their guidelines on when to use an agent-based simulation approach, Rand and Rust (2011) list the following factors: (i) medium-sized numbers; (ii) local and potentially complex interactions; (iii) heterogeneity; (iv) a rich environment; (v) temporal aspects; and (vi) adaptive agents. The first indicator refers to the number of agents representing individual stakeholders in simulation runs. If we have only two agents or players-for example, one manufacturer and one "average consumer"-game theory would be the better approach. In contrast, if we need to model hundreds of thousands of stakeholders, a statistical regression would likely lead to better results. However, in our application case, we have a medium number of agents - a few agents representing manufacturers and several hundred or thousand agents representing (groups) of consumers. As for the second indicator mentioned by Rand and Rust-local and potentially complex interactions - our case concerns consumer agents that make decisions to purchase clothes while being influenced by peers within their social network, which may result in direct or indirect interactions impacting the purchasing decision. The third indicator concerns heterogeneity, which is obviously applicable in our case as we are considering several manufacturer agents following different supply chain strategies, resulting in several products, and heterogeneous consumer agents that differ in terms of their preferences for product attributes, their socio-demographics, and their purchase and communication behavior. The fourth indicator refers to rich environments that are present in our model in the form of interactions between stakeholders through their social networks. While these factors indicate the potential applicability of agent-based simulation, 
the penultimate indicator - a temporal aspect—is necessary. In our application case, we want to analyze changes in the market resulting from the changing behavior of manufacturer agents and changes in consumer agents' behavior over time. The last (sufficient) indicator refers to the adaptiveness of agents. To some degree, this is also met in our model as consumer agents may change their attitudes (i.e., their evaluated perception) toward product attributes based on the influence of their social networks or by gaining first-hand experience with products.

\section{Agent-based model of an apparel market}

As we are primarily interested in comparing alternative supply chain strategies, we accordingly focus on two types of products, namely, basic products and fashion products, as well as two groups of stakeholders: manufacturer agents and consumer agents. Both groups of agents are characterized by parameters (e.g., a consumer's communication habits and behavior) and variables (e.g., a consumer's attitudes toward a product's attributes). Manufacturer agents produce clothing and decide (i) what kind of product to create at a production site (e.g., in Europe or in the Far East), (ii) at what time the product should be available in stores, (iii) in what quantity, and (iv) at what price it is to be offered to consumer agents. Furthermore, manufacturer agents can advertise their products in order to increase the level of awareness among consumers. Products are offered at points of sale (e.g., online or stationary trade), which may or may not be accessible to specific consumer agents. For example, online shops are accessible to all consumer agents, whereas some local shops are accessible primarily to consumer agents located within a reasonable geographic distance. Consumer agents purchase products based on their individual preferences and learn about product attributes through firsthand experience. Interaction (e.g., word-of-mouth communication) among the agents occurs within the social networks in which they are embedded. Figure 1 provides an overview of the entities and dynamics in our agent-based model of an apparel market.

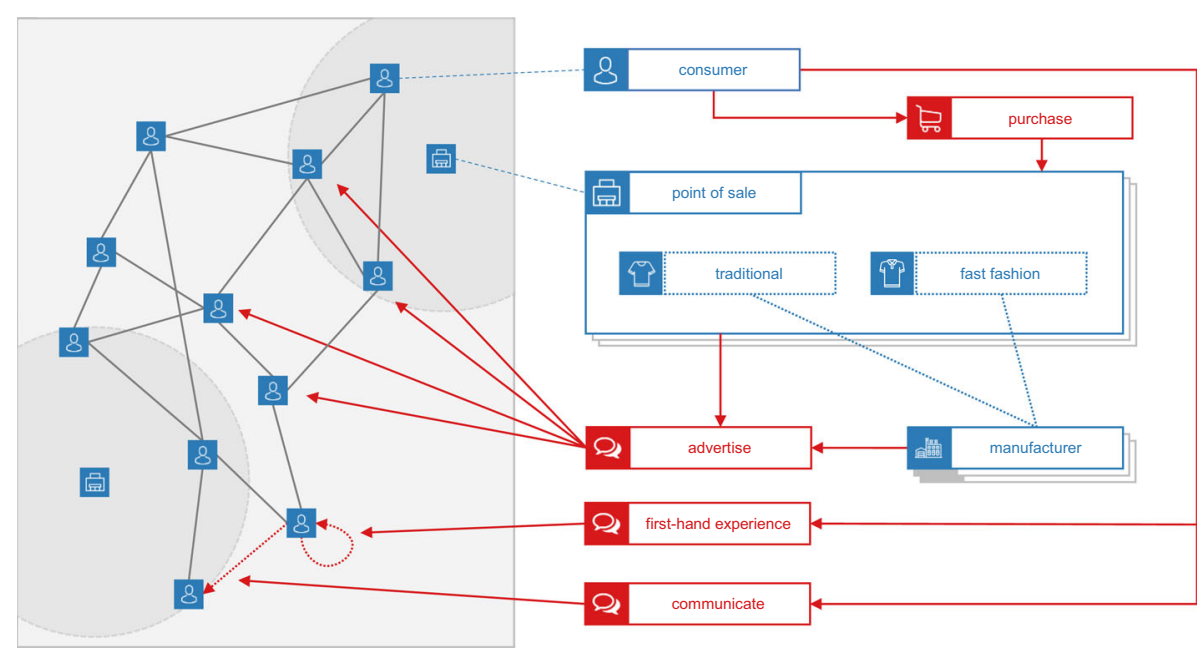

Fig. 1 Agent-based market model 


\subsection{Model entities}

\subsubsection{Product and manufacturer}

The simulation accounts for a set $P$ of products (i.e., clothes) indexed by $i=1, \ldots, I$, where $I$ represents the total number of products (i.e., $I=|P|$ ). Products have attributes indexed by $j=1, \ldots, J$, whereby $J$ is the total number of attributes within the set of attributes $A(J=|A|)$. Every product $P_{i}$ is associated with a manufacturer agent indexed by $k=1, \ldots, K$ within the set $M(K=|M|)$. For the sake of simplification, we do not distinguish between manufacturers and retailers in this basic model, that is, manufacturer agents both produce and sell their products directly to consumers. From the viewpoint of the manufacturer agents, products are characterized by cost per unit, which depends on the chosen production site. In each simulated period, a given volume of products is produced and made available for consumer agents until the product is either sold out or removed from the market by the manufacturer agent.

\subsubsection{Point of sale}

Points of sale (POS), indexed by $s=1, \ldots, S$ within the set $R$, have specific geographical positions and are individually characterized, for example, by product assortment and storage volume $(S=|R|)$. Each point of sale receives a certain number of different products, each of which may have its own individual price. Furthermore, a point of sale can engage in individual advertising campaigns. Regarding stationary trade, a physical point of sale is available to consumer agents within a certain geographical radius. In contrast, online points of sale make all products available regardless of the consumer's geographic position, as is the case for the customary online trading platform.

Our research focuses on comparing the traditional fashion strategy and the fast fashion strategy, and we do not want to impact this decision with the issue of the availability of one type of fashion item or another to only a subset of consumers. Therefore, we opted to implement a single online shop having all products offered by all manufacturers. Hence, every product is accessible to every consumer.

\subsubsection{Consumer}

We consider a set $C$ of heterogeneous consumer agents indexed by $n=1, \ldots, N(N=|C|)$, which are assigned to a specific geographical position. Consumer agents have individual awareness aware $_{i, n}^{\text {prod }}$ of products; aware $_{i, n}^{\text {prod }}=0$ if consumer $n$ is not aware of the existence of product $i$, otherwise $\operatorname{aware}_{i, n}^{\text {prod }}=1$. The same holds for the consumer agents' awareness of product attributes $\operatorname{aware}_{i, j, n}^{\text {attr }} \in\{0,1\}$ and awareness of points of sale $\operatorname{aware}_{n, s}^{\text {pos }} \in\{0,1\}$. Consumer agents become aware of products by word of mouth, advertising, or while strolling through the (online) shop.

Consumer agents have individual attitudes regarding the corresponding attributes (attitude $e_{i, j, n}^{\mathrm{attr}}$ ) of each known product. Their heterogeneous preferences are represented by individual part-worth utility functions $u_{j, n}()$. The attitudes are formed over time by word of mouth, first-hand experience, and advertising. Finally, consumer agents are also characterized by their individual purchase and communication behavior (see Sect. 3.2). 


\subsubsection{Social network}

The social network used in this model is based on an adapted Barabási-Albert network (Barabási and Albert 1999), which exhibits strong clustering and several network hubs, both of which are characteristic of social networks (see Barabási and Bonabeau 2003; Squazzoni et al. 2014). Our variant of this social network-generating algorithm considers agents that are located close to each other to have a higher probability of being connected than agents that are separated by large distances (following a suggestion by Stummer et al. 2015).

Technically, the probability that an agent $a$ is connected with another agent $b$ is proportional to $d(a, b)^{\alpha} \cdot \operatorname{deg}(b)^{\beta}$, where the function $d()$ represents the Euclidean distance between agent $a$ and agent $b$ (normalized to an interval $[0,1]$ ). The exponent $\alpha$ is typically negative so that a smaller distance leads to a higher probability of a connection between two agents. Function $\operatorname{deg}(b)$ gives the number of connections that agent $b$ already has with other agents (once again normalized to an interval $[0,1]$ with respect to the minimum number and the maximum number of connections for any agent that is already part of the network). Parameter $\beta$ is typically positive so that agents with many existing connections are chosen with a higher probability for a new connection. Thus, a few consumer agents have a particularly high number of connections. These agents can be used to analyze the role of influencers in apparel markets.

The social network-generating algorithm produces the weighted and directed graph $G=$ $(C, L)$, where $C$ is the set of consumer agents and $L$ is the set of communication links. Several alternative variants of social networks (one for each random seed) are generated in advance by iteratively adding agents one by one and deciding on the connections for each of them. A particular social network is then imported during the initialization of each run of the agent-based simulation.

\subsection{Model dynamics}

In our model, consumer agents can gain information about products and product attributes by communicating with other consumer agents, from advertising, as well as through normative social influence. Furthermore, consumer agents purchase products and thereby, gain firsthand experience.

\subsubsection{Communication}

Consumer agents communicate with their peers in the social network about products and product attributes. Procedurally, a set of possible topics (i.e., product-attribute pairs) is generated. The corresponding algorithm follows intuitive communication behavior, that is, peers might communicate about a specific product and all its attributes, or about a specific product attribute and its value in all products, or about one explicit product-attribute pair (see Algorithm 1). The selection of actual communication topics is based on the following assumptions (also used by Stummer et al. 2015): (i) consumer agents tend to talk after obtaining new information that change their individual utility of a product attribute; (ii) the larger the change in the estimated partial utility, the higher the probability of communication; (iii) consumers are more likely to pass on information that causes a negative change in the estimated utility; (iv) a basic requirement for talking about a product-attribute pair is that at least one of the agents is aware of that attribute. We implement these principles by making use of a specified function that assigns the probability of a product-attribute pair being selected to the list of possible 
communication topics. Finally, the two consumer agents communicate about topics on that list and inform each other about their own current attitude with respect to the respective product-attribute pair.

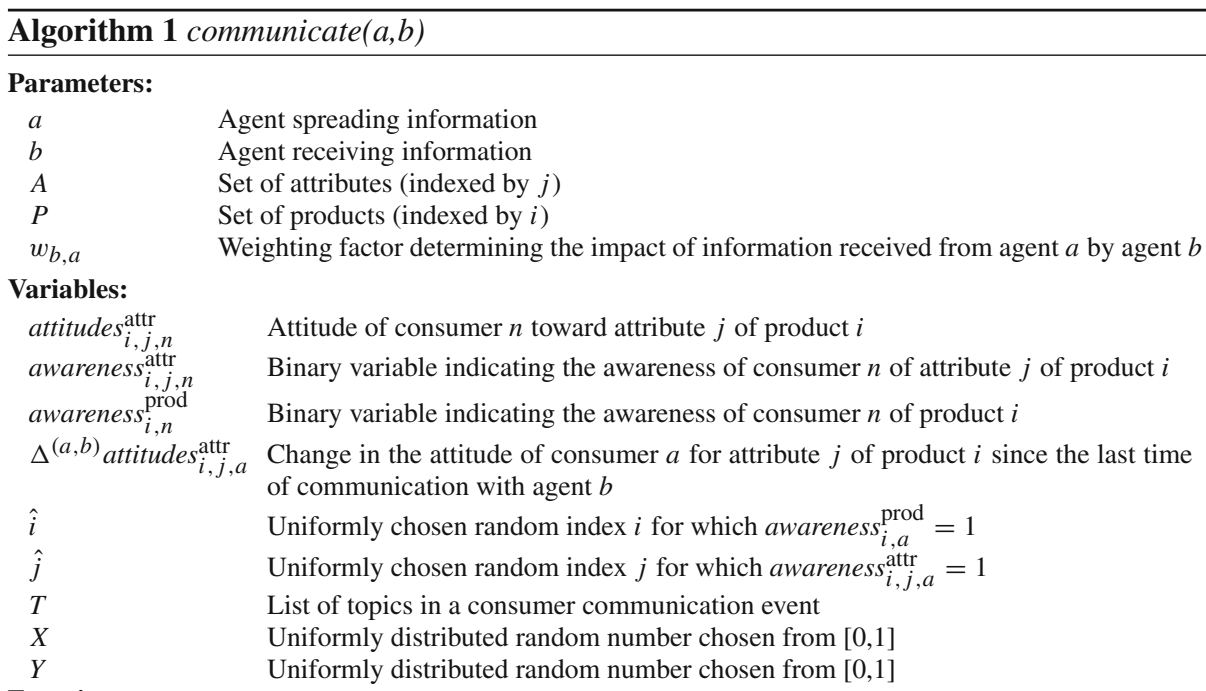

\section{Functions:}

$$
p^{\text {select }}\left(\Delta^{a, b} \text { attitudes } \mathrm{attr}_{i, a}^{\mathrm{atr}}\right)
$$

processInformation $(b, i, j$, value,$w)$
Function that assigns a word-of-mouth propagation probability based on a given change in attribute utility valuation with an asymmetric U-shaped form to illustrate that the larger the change in the estimated partial utility, the higher the probability that the agent will pass on the information

Function that processes the incoming information value for attribute $j$ of product $i$ into attitudes $s_{i, j, b}^{\text {attr }}$ with weight $w$

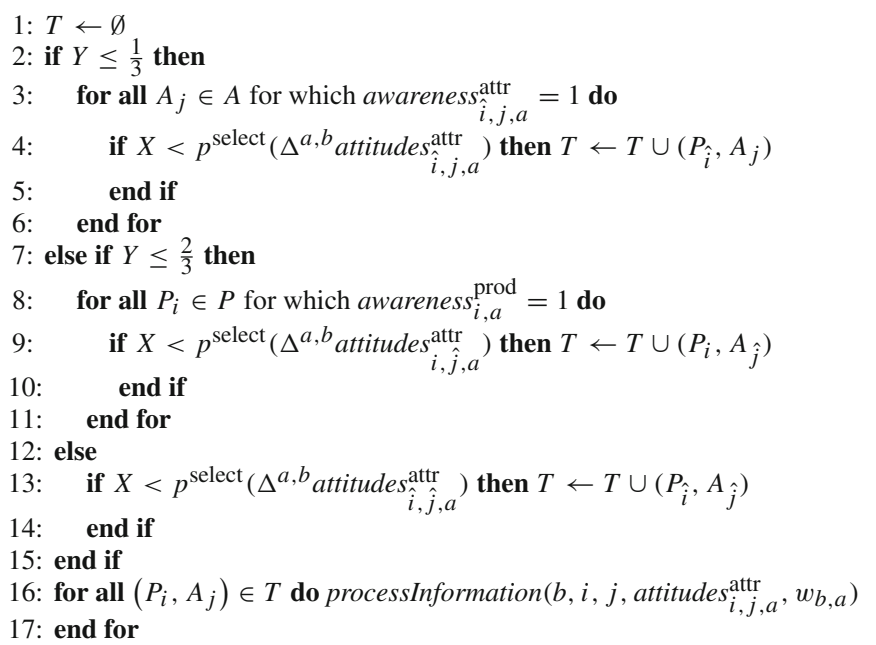

Manufacturer agents may advertise their products, thereby informing selected consumer agents about the products and their attributes through mass media (e.g., print and TV) and 
social media (e.g., influencers). Our research is primarily concerned with comparing fashion supply chain strategies, and modeling consumers' inducement toward purchasing a new fashion item is not in the foreground of our research objectives. Therefore, we did not distinguish between specific advertising measures, but subsumed the possible measures to an overall generic advertising measure with which a manufacturer agent could inform consumer agents.

Technically, advertising is a form of one-way communication. A randomly chosen number of consumer agents is reached by an advertising event only within a specific geographical position or specific consumer segment. The selected agents are then-with a given probability-influenced by advertising. As in the case of communication between two consumer agents, two cases can be distinguished: (i) a consumer agent is already aware of the product, and the advertising event influences the agent's current attitudes; or (ii) the consumer agent is made aware of the product by the advertising event. The procedure dictating the information inflow is similar to the one that has been described above. The information gained by each consumer agent from the advertising event is weighted by the agent's trust in advertising. The manufacturer agent decides on what is communicated to the consumer agents, although this information may not necessarily reflect the true (attribute) value. For the corresponding algorithm, see Algorithm 2.

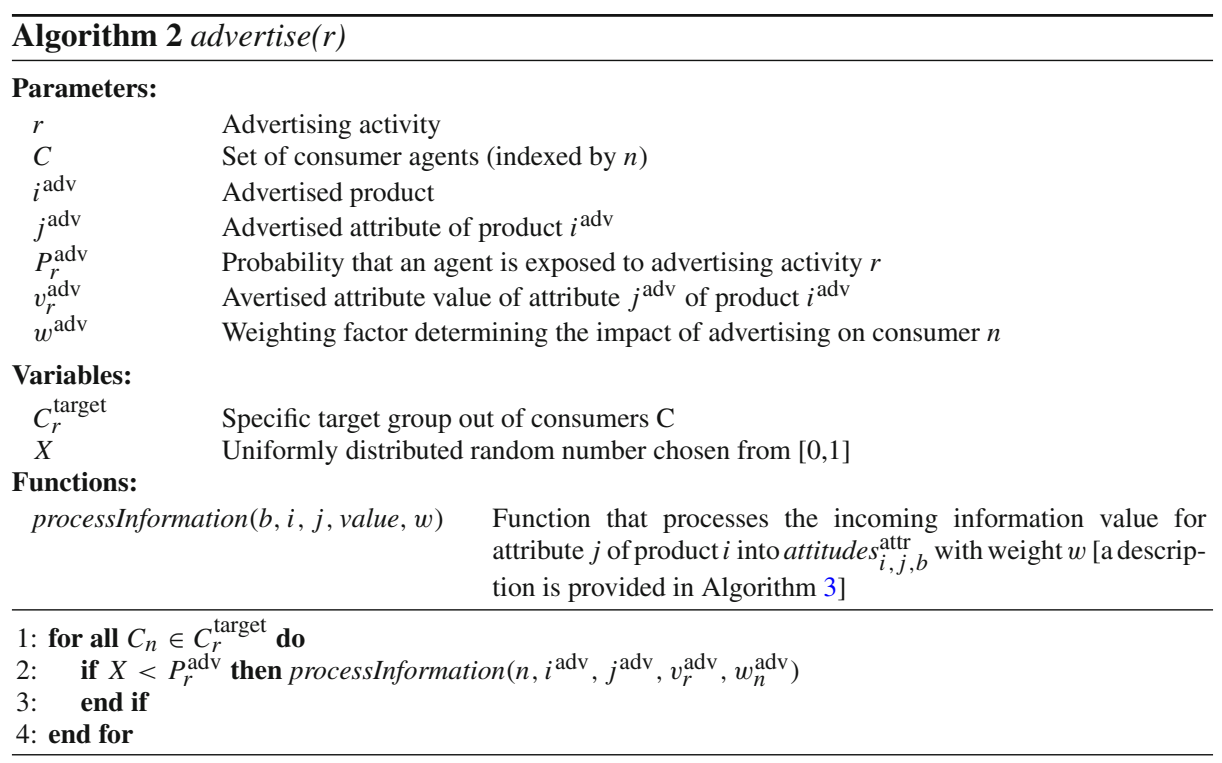

The obtained information is weighted to represent the varying credibility of information sources. When agents $a$ and $b$ exchange information, the weighted information on the product-attribute pair $(i, j)$ of agent $b$ is updated. We define $V_{i, j, b}$ as the weighted information that agent $b$ has before talking to agent $a$ about the product-attribute pair $(i, j) . W_{i, j, b}$ is the sum of the current weights. The current attitude of agent $b$ about attribute $j$ of product $i$ is calculated as attitudes $s_{i, j, b}^{\mathrm{attr}}=V_{i, j, b} / W_{i, j, b}$. After exchanging information with agent $a, V_{i, j, b}$ and $W_{i, j, b}$ are updated as $V_{i, j, b}:=V_{i, j, b}+$ attitudes attr ${ }_{i, j, a} \cdot w_{b, a}$ and $W_{i, j, b}:=W_{i, j, b}+w_{b, a}$. If we assume that agent $b$ is unaware of the product-attribute pair $(i, j)$, then agent $b$ receives the current attitude about the attribute of agent $a: V_{i, j, b}:=\operatorname{attitudes}_{i, j, a}^{\mathrm{attr}} \cdot w_{b, a}$ 
and $W_{i, j, b}:=w_{b, a}$. For a formal description of the algorithm underlying this communication process, see Algorithm 3.

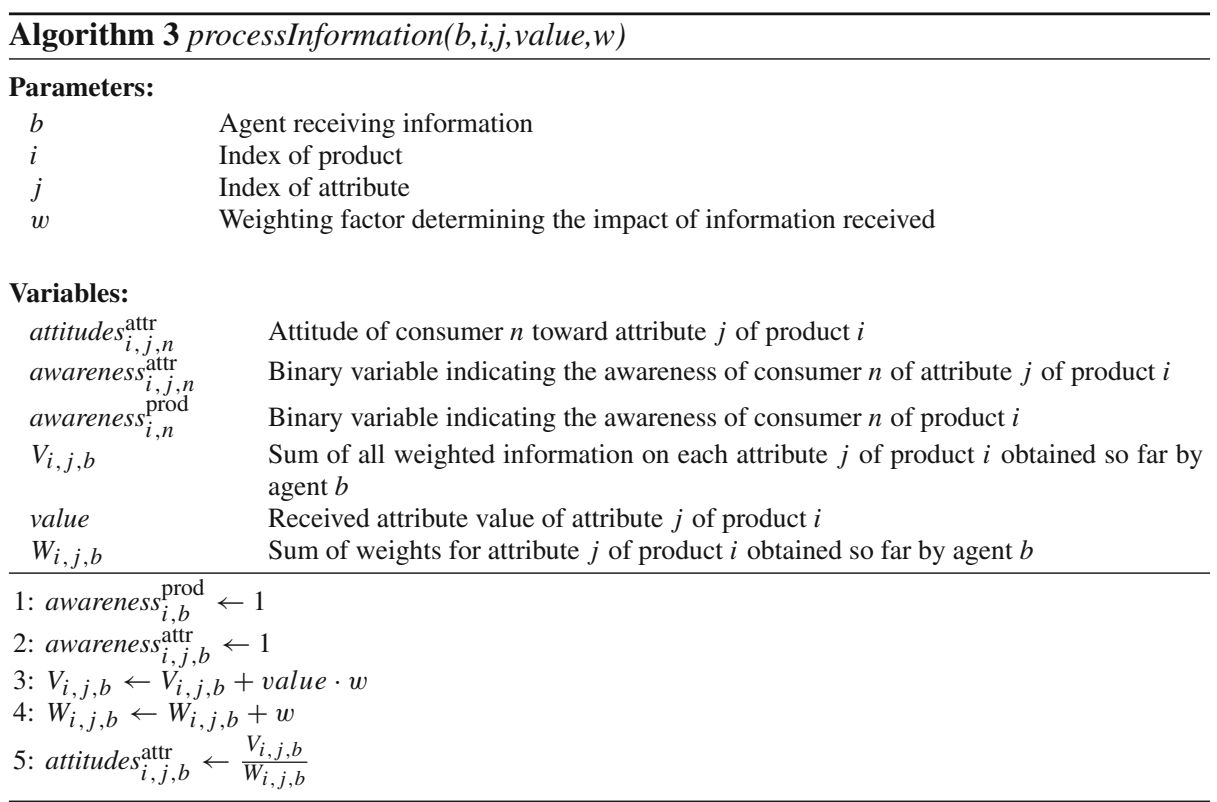

\subsubsection{Normative social influence}

Consumers might also be affected by "social influence" exerted through their immediate peers in the social network (especially, friends and family) - they consider the attitudes of others and keep in mind the products owned by their peers. The impact of normative social influence increases over time, not least because of social media and direct communication opportunities (see Aral and Walker 2014; Risselada et al. 2014).

The actual effect of normative social influence is based on group size, importance of group affiliation, and spatial and temporal proximity of other group members, according to the social impact theory of Latané (1981). In our model, normative social influence is based on the proportion of peers - that is, the directly connected agents-owning the respective type of product (following Delre et al. 2007). It affects the purchase decisions (as suggested by Butcher et al. 2002; Cialdini and Goldstein 2004; Delre et al. 2010), as can be seen in the utility function described in the succeeding subsection.

\subsubsection{Purchase}

Consumer agents seek to purchase clothes at individual temporal intervals, randomly chosen from a triangular distribution based on external (given) data. Accordingly, the model accounts for both fixed individual purchase intervals and spontaneous purchases. When at a shop, a consumer considers all known products available at the shop in their decision. 
Next, the utility of each of these products is calculated. By summing up the part-worth utility of each attribute $j$, the utility of the product $i$ is determined as

$u_{i, n}=u_{1, n}\left(\right.$ price $\left._{i, t}\right)+\sum_{j=2}^{J} u_{j, n}\left(\operatorname{attitudes}_{i, j, n}^{\mathrm{attr}}\right) \cdot \operatorname{awareness}_{i, j, n}^{\mathrm{attr}}+$ norm $_{i, n} \cdot w_{n}^{\mathrm{norm}}+\epsilon^{\mathrm{prod}}$.

We assume that the price (i.e., the attribute with index $j=1$ ) is perfectly visible to the consumer agent. Hence, the real price is used in the part-worth utility function. The impact of normative social influence $\left(\right.$ norm $_{i, n}$ ) on consumer $n$ regarding the product $i$ is represented by the weighting factor $\left(w_{n}^{\text {norm }}\right)$. Possible mistakes and additional minor factors that are not explicitly considered by the model are subsumed in an error term $\epsilon$.

Ultimately, the consumer agent purchases the product that maximizes the total utility (the agent's first choice). For a formal description, see Algorithm 4.

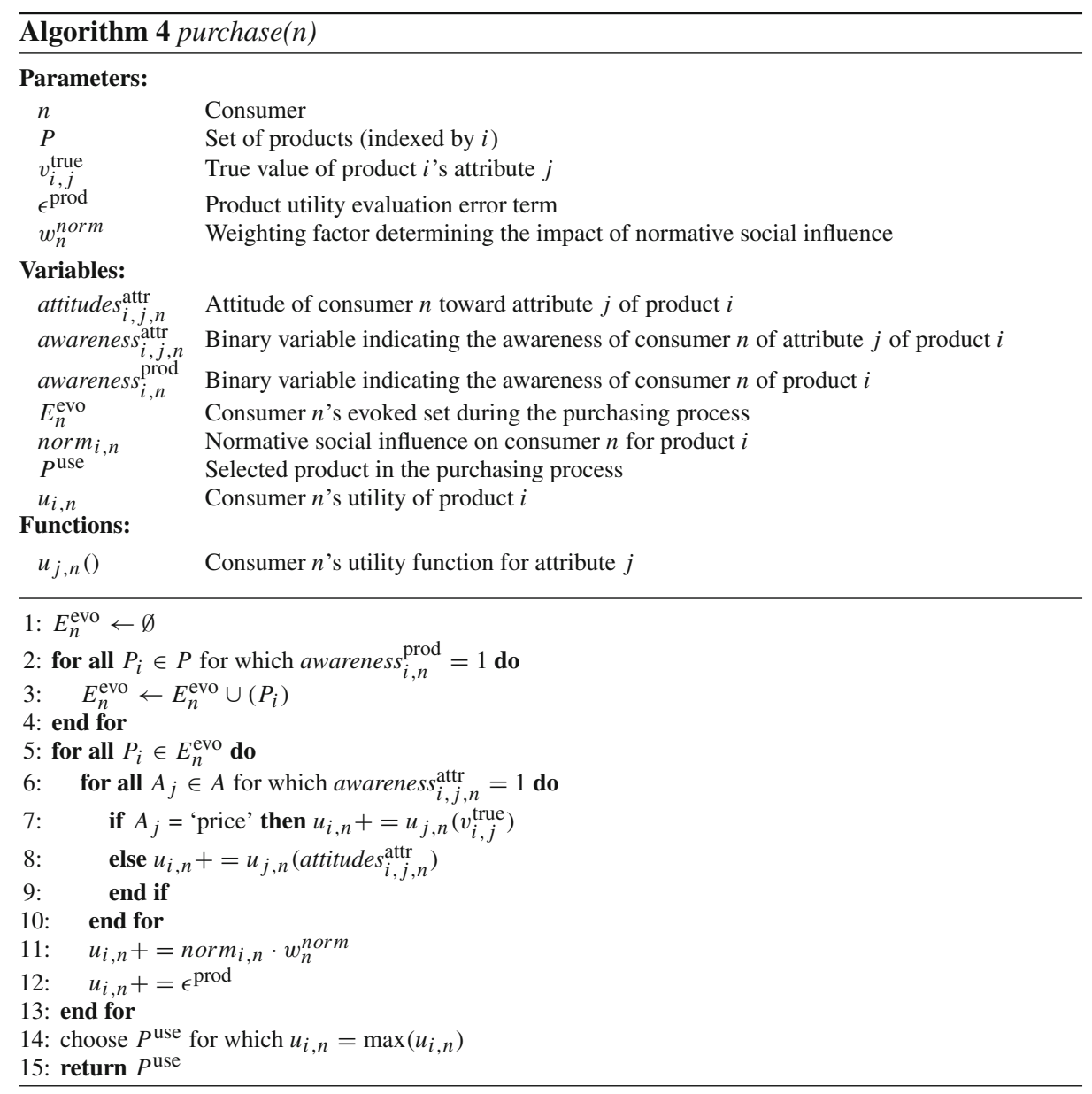




\subsubsection{First-hand experience}

After purchasing a product, the consumer agent obtains "true" information about the product attributes through first-hand experience at a certain point in time after the purchase and before making subsequent product purchases. The information about the product is updated in the same way as in the case of gaining information from another consumer agent (see Sect. 3.2.1). For a formal description of the algorithm underlying first-hand experience, see Algorithm 5.

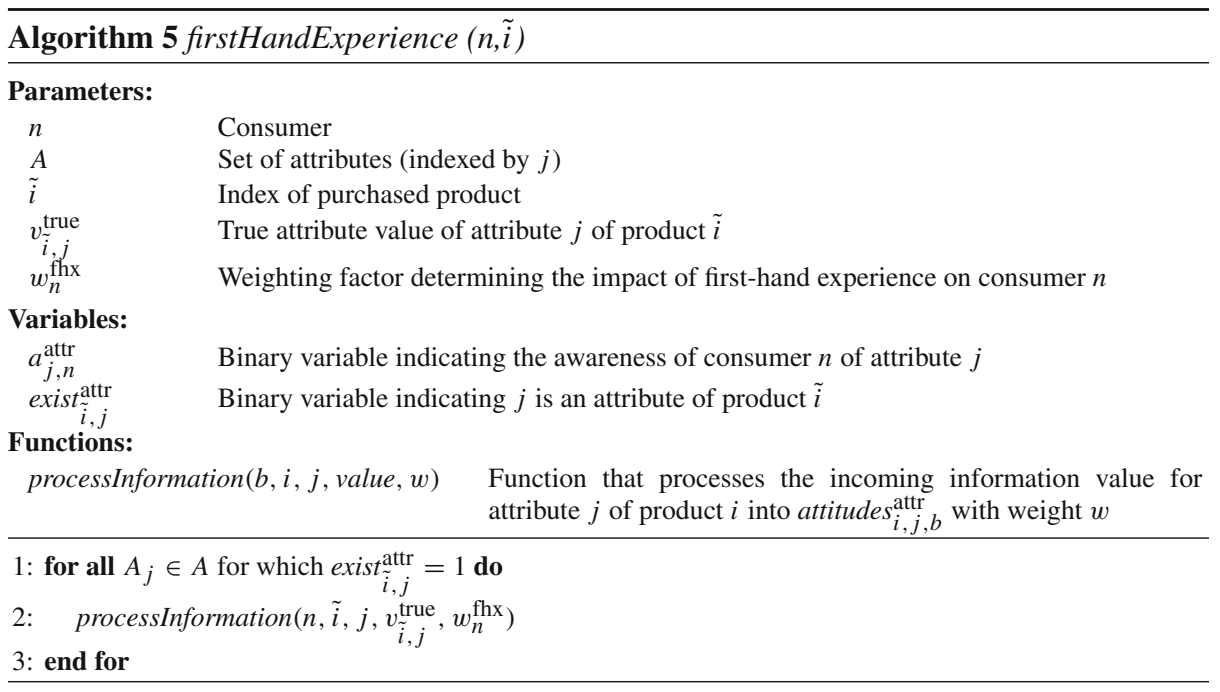

\subsection{Differentiation of the agent-based model from an earlier approach}

Our agent-based model of an apparel market was inspired by the work of Stummer et al. (2015), who introduced an agent-based model for studying the diffusion of a new product in the fuel market. As the apparel market obviously differs from the fuel market, we had to extend this earlier model in several important respects. First, in the model by Stummer et al. (2015), no supply side limitations are considered, whereas in our apparel market model every manufacturer can decide on order times and order quantities following the chosen supply chain strategy and, thus, stock-outs are possible. Second, end-of-season clearance sales are prevalent in the fashion industry and therefore considered in our model. Third, normative social influence is a factor to be considered in the consumer agents' purchasing decision, as wearing apparel can be observed publicly and can therefore influence the purchasing behavior of consumers. In contrast, social influence does not play a role in the fuel market model by Stummer et al. (2015) - they assumed that other consumers could hardly recognize which type of fuel has been purchased by just seeing a consumer driving their car. 


\section{Analytical versus agent-based model}

We choose the prominent paper by Cachon and Swinney (2011) as a benchmark for our efforts to demonstrate the advantages of our agent-based simulation model for evaluating supply chain strategies in the apparel industry. In the initial baseline scenario, we show that the agent-based simulation model can replicate the core results obtained by Cachon and Swinney, provided we restrict the complexity of our model appropriately. Subsequently, in Scenarios $\mathrm{A}$ and $\mathrm{B}$, we demonstrate the effect of consumer heterogeneity on the market results of the supply chain strategies under scrutiny. To this end, we make consumer agents heterogeneous with respect to both their preferences for fashion attributes and their initial attitudes toward these attributes. The reason for this is that both (i.e., preferences and attitudes) together determine the consumers' utility value determining their purchasing decision between fast fashion and traditional fashion (see Algorithm 4).

The parameterization and initialization of our agent-based simulation in this comparison are throughout based on the corresponding values established by Cachon and Swinney (2011). Accordingly, the two products (a traditional and a fast fashion product) are characterized by the product price, value, and cost, all calculated according to the work by Cachon and Swinney. As for the consumers' (average) needs and preferences, we test the same 12,150 alternative parameter combinations.

In the baseline scenario, the simulation model is strictly constrained to closely reflect the model by Cachon and Swinney (2011). Especially, all consumers considered in this scenario are assumed to be homogeneous with respect to their preferences, attitudes, and behavior. We still allow word-of-mouth communication between them but this does not show any effect since every individual attitude is set to be identical from the beginning. In the two other scenarios, preferences regarding product value and price vary among the consumers. In Scenario A, the individual part-worth utilities for the product value and the product price of each consumer are randomized within a $25 \%$ range $(\Delta= \pm 25 \%)$, while in Scenario $\mathrm{B}$, the consumers are distinctly more diverse and the part-worth utilities are randomized within a $50 \%$ range $(\Delta= \pm 50 \%)$. However, the average consumer behavior still equals the representative consumer envisioned by Cachon and Swinney, as parameterized in the baseline scenario. In both scenarios with heterogeneous consumers, individual initial attitudes are drawn from a triangular distribution with the true product value as the expected value, with the minimum value being set at $75 \%(50 \%)$ of the true value, and the maximum value being set at $125 \%(150 \%)$ of the true value. Since the product price is observable before the purchase, the consumers' attitudes toward the product price are always set to the true product price in our simulation. The purchasing and the communication behavior of the consumer agents are initialized based on data from our empirical study on consumer behavior, which is described in the succeeding section (an overview of consumer characteristics is depicted in Fig. 2 in Sect. 5.1).

Each scenario is simulated with 1000 interacting consumer agents. We simulated a period of ten years, with multiple purchase processes and several communication events for each consumer. It is noteworthy that Cachon and Swinney (2011), in contrast, modeled only a single purchase of one average consumer in each of their 12,150 instances.

In the first set of simulation runs (i.e., in the baseline scenario with homogeneous consumer agents), fast fashion was the more profitable choice in 9039 out of 12,150 instances $(74.4 \%)$ with respect to both market shares and profits. The calculation of profits again followed the approach proposed by Cachon and Swinney (2011). Our simulation results correspond closely with the results reported by Cachon and Swinney where fast fashion was the better choice 
Table 1 Homogeneous consumers versus heterogeneous consumers

\begin{tabular}{llll}
\hline & Homogeneous consumers & \multicolumn{2}{l}{ Heterogeneous consumers } \\
& \multicolumn{1}{c}{ Scenario A } & Scenario B \\
& $\Delta=0 \%, \epsilon=0 \%$ & $\Delta= \pm 25 \%, \epsilon=5 \%$ & $\Delta= \pm 50 \%, \epsilon=5 \%$ \\
\hline Share of instances, in which fast fashion is the better choice & & \\
(i) Based on market share (\%) & 74.4 & 66.6 & 56.6 \\
(ii) Based on profits (\%) & 74.4 & 75.4 & 69.9 \\
\hline
\end{tabular}

in 9046 cases $(74.5 \%)$. This correspondence is unsurprising, as we specifically intended to replicate the market behavior of their model through our agent-based simulation.

In the second set of simulation runs, we assume that consumers are heterogeneous in their preferences for product value and price as well as their initial attitudes (while all other parameters and instances remain unchanged). In other words, in contrast to Cachon and Swinney's assumption, some consumer agents, for example, prefer products with a higher (lower) product value or price and vice versa.

The results from the two sets of simulation runs are shown in Table 1. It should be remembered that heterogeneity in Scenario B is larger than in Scenario A, while in the baseline scenario, there is no heterogeneity among consumers at all. The epsilon is used as an error term in the additive utility function to represent the remaining minor factors for the purchasing decision.

In terms of profits, the advantage of the fast fashion strategy remains nearly unaffected, that is, it is not strongly affected by small variances in the individual part-worth utilities of consumer agents. However, with respect to market shares, it can be observed that accounting for heterogeneity among consumers yields simulation results which suggest that the fast fashion strategy is advantageous in fewer instances than when assuming identical consumers (i.e., in the baseline scenario). Most notably, this is the case in Scenario B, in which fast fashion is deemed favorable in only 6,876 out of 12,150 instances $(56.6 \%)$, down from 9,039 instances $(74.4 \%)$.

The observation on market shares may at first sight appear surprising or even counterintuitive, but one has to keep in mind the mechanics of how heterogeneity works in the simulation model. For the majority of consumer agents, the changes in their preferences and attitudes due to an increasing heterogeneity do not impact their final decision behavior, and, thus, they purchase the same product as before. The other consumer agents-that is, consumer agents whose preferences and attitudes deviate more substantially from the representative consumer envisioned by Cachon and Swinney-are more interesting. In these cases, the deviation might either cause an even more pronounced desire for fast fashion (traditional fashion) or push them toward traditional fashion (fast fashion). For our results this means the following: As nearly three quarters of homogeneous consumer agents have opted for the fast fashion product, the number of consumer agents switching from fast fashion to traditional fashion after introducing heterogeneity is larger than vice versa. In a nutshell, in a market, in which the representative consumer is, in terms of preferences and attitudes, positioned near the brink of purchasing a different type of product (as is the case in the market parameterized by Cachon and Swinney), increasing the heterogeneity of consumers will reduce the dominance of the strategy favored in the homogeneous scenario. Note that these mechanics, depending on whether the parameterization in the homogeneous scenario favors fast fashion or traditional products, might work in two different directions. For the parameter setting 
in our approach, the representative consumer in the homogeneous case favors fast fashion products. Therefore, increasing heterogeneity makes the fast fashion strategy less attractive for the supplier. In contrast, once in the homogeneous scenario traditional products are preferred, increasing heterogeneity would lead to growing numbers of consumer agents buying fast fashion products. However, since one intention of this paper is to compare the simulation approach with the analytical approach by Cachon and Swinney (2011), we started with the parameters being used by Cachon and Swinney and, thus, we situated this simulation in a market that is characterized by an already dominating - and with respect to this dominance maybe even overshooting - fast fashion strategy. Our simulation results indicate that, in such a setting, it is even more important to suitably consider the heterogeneity of consumers.

\section{Sample application}

To study in a more general setting whether the traditional or fast fashion strategy is the more suitable one, we model a simplified (fictitious) apparel market that initially comprises two manufacturers. A third manufacturer enters the market later, thus increasing the competition and shifting the balance in the market. One of the preexisting manufacturers has established a traditional supply chain and accordingly offers a basic product produced in the Far East that is available at the point of sale for the entire season. As it is common practice, this manufacturer features two collections - one for the summer season and another for the winter season. Moreover, each collection of products is offered at reduced sale prices at the end of each season. The other initial manufacturer follows a fast fashion strategy and hence offers two types of products - a fashion product commonly produced near the points of sale and a basic product. This manufacturer changes its collection regularly every few weeks. Fast fashion merchandise is not offered at sale prices, and unsold products are simply withdrawn from the point of sale, which is associated with additional costs. Both the traditional manufacturer and the fast fashion manufacturer can advertise their own products.

In our simplified market, all basic and fashion products are differentiated by only three attributes: (i) the trendiness factor, (ii) quality, and (iii) price. While quality and price are the most relevant criteria for fashion purchases (Hayllar et al. 2019), basic products are differentiated from fashion products by the trendiness factor, which indicates how well a product matches the latest fashion trend(s). By definition, a fast fashion product has a higher trendiness factor. The quality factor relates to the craftsmanship and the type of material used in the product. The price is the in-store purchase price. Moreover, each product type has unique production costs, which are higher for fashion products.

Every consumer has individual attitudes and preferences regarding these attributes which are described by utility functions for each attribute (see Sect. 3.1.3). Consumer agents' attitudes can be influenced by communication within their social network, manufacturer advertising, and, of course, by their own first-hand experience following a purchase. The obtained information is weighted individually depending on how much the agent trusts the information source-first-hand experience is the most trustworthy, followed by word-ofmouth communication, while advertising is deemed to be the least trustworthy. Consumer agents purchase a new product and communicate with others in their social network at individual time intervals.

As we are primarily interested in comparing alternative supply chain strategies, we limit the diversity of agents and agent behavior in this sample application with respect to the shopping behavior of consumers, the points of sale, and the marketing measures being applied, because 

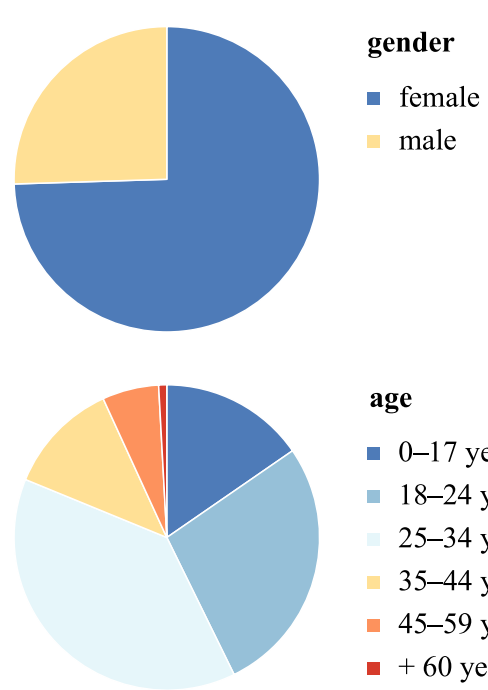

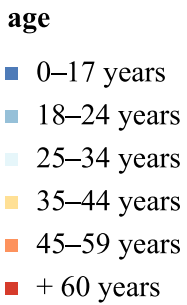

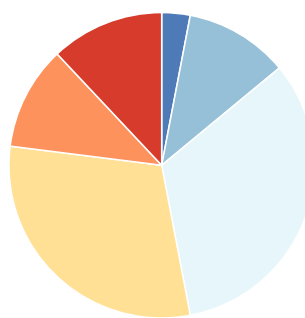

communication

- never

7 days

30 days

90 days

180 days

- 360 days

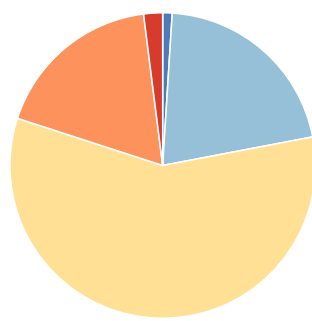

purchase

- 7 days

- 30 days

90 days

180 days

- 360 days

Fig. 2 Consumer characteristics from empirical study

more diversity in these respects does not contribute toward answering our research question. However, the agent-based model could still cover other characteristics of the apparel market (e.g., shopping as a favorite pastime for consumers, various types of brick-and-mortar outlets on specific geographical positions, and influencer marketing) once these aspects play a role in investigating further research questions.

\subsection{Parameterization}

The parameterization of consumers, products, and manufacturers, as well as other dynamics of our simplified apparel market is based on aforementioned literature (esp. Cachon and Swinney 2011), data from research on manufacturer websites and online shops (e.g., Zara and $\mathrm{H} \& \mathrm{M})$, and data from an empirical study we carried out in preparation to our simulation experiments.

This survey was answered by a total of 100 participants (for some descriptive statistics, see Fig. 2). We used the respondents' answers to derive the parameters for consumer behavior, that is, communication frequency, purchase interval, and trust in communication and advertising. Consumer preferences - that is, the (part-worth) utilities for the attributes - were determined by a conjoint analysis as part of the empirical study. Although this sample is obviously not representative, it serves to demonstrate the potential of our approach to model apparel markets more realistically.

The consumer agents are geographically distributed according to the population based on German postal code areas. To parameterize 1,000 consumers in our simulation, we used each of the 100 participants from our survey as a role model for 10 consumer agents and assigned them corresponding — although slightly varied - parameter settings.

The attributes of products vary depending on the scenario, the manufacturers' chosen strategy, and the additional measures applied by the management (e.g., increasing the product quality). Table 2 provides the values for Scenario 1, with no additional measures applied. The quality of products is set within a range from 0 to 1 , where 0 represents the lowest 
Table 2 Products and product attributes in Scenario 1

\begin{tabular}{llllll}
\hline & Products & & & \\
\cline { 2 - 5 } & basic $^{\mathrm{T}}$ & basic $^{\mathrm{F}}$ & fashion & & \\
& & & & & \\
Pasic & & fashion $^{\mathrm{F}^{+}}$ \\
Product attributes & & 0.25 & 0.75 & 0.25 & 0.70 \\
Quality & 0.05 & 0.50 & 0.50 & 0.43 & 0.50 \\
Price & 0.37 & $€ 40.95$ & $€ 59.95$ & $€ 44.95$ & $€ 54.95$ \\
\hline
\end{tabular}

quality. Likewise, the trendiness factor is set between 0 and 1, with 1 indicating that the product perfectly matches the latest fashion trend. Note that the superscripts $\mathrm{T}$ and $\mathrm{F}$ refer to existing traditional or fast fashion manufacturer, while the superscripts $\mathrm{T}^{+}$and $\mathrm{F}^{+}$refer to the respective new competitor as introduced in the succeeding subsection.

In the apparel market modeled for this sample application, all products are available in an online store. Thus, the geographical location of consumer agents (in Germany) only plays a role in setting up the social network.

Furthermore, manufacturers are responsible for all aspects of the introduction of their products to the market. Depending on their supply chain strategy, manufacturers act as traditional or fast fashion manufacturers. A traditional manufacturer replaces the assortment of fashion goods twice a year. Each of the two seasons ends with a two-week sale where products are offered at a $20 \%$ discount on the original product price. The fast fashion manufacturer, in contrast, changes its collection every four weeks and does not offer any sale. Both manufacturers generate revenues for all sold products and carry production costs that are dependent on their choice of strategy. For calculating profits, we follow Cachon and Swinney (2011), who suggest a profit margin of $48.7 \%$ for basic products and $27.7 \%$ for fashion products.

\subsection{Scenarios and management measures}

In this sample application, we test six scenarios that differ in terms of the market shares of the two initially existing manufacturers $\mathrm{T}$ and $\mathrm{F}$ at the beginning of the simulation runs and the supply chain strategy of the new competitor $\mathrm{T}^{+}$or $\mathrm{F}^{+}$entering the market (the scenarios are listed in Table 3). The agent-based simulation at hand might help this new manufacturer decide which strategy to adopt.

Table 3 Market scenarios

\begin{tabular}{|c|c|c|c|c|c|}
\hline & \multicolumn{2}{|l|}{ Manufacturer T } & \multicolumn{2}{|l|}{ Manufacturer F } & \multirow{2}{*}{$\begin{array}{l}\text { New competitor } \mathrm{T}^{+} \text {or } \mathrm{F}^{+} \\
\text {Products }\end{array}$} \\
\hline & Market share (\%) & Products & Market share (\%) & Products & \\
\hline Scenario 1 & 33.3 & basic $^{\mathrm{T}}$ & 66.6 & basic $^{\mathrm{F}}$, fashion ${ }^{\mathrm{F}}$ & basic $^{\mathrm{F}^{+}}$, fashion $\mathrm{F}^{+}$ \\
\hline Scenario 2 & 50.0 & basic $^{\mathrm{T}}$ & 50.0 & basic $^{\mathrm{F}}$, fashion ${ }^{\mathrm{F}}$ & basic $\mathrm{F}^{+}$, fashion $\mathrm{F}^{+}$ \\
\hline Scenario 3 & 66.6 & basic $^{T}$ & 33.3 & basic $^{\mathrm{F}}$, fashion ${ }^{\mathrm{F}}$ & $\operatorname{basic}^{\mathrm{F}^{+}}$, fashion $\mathrm{F}^{+}$ \\
\hline Scenario 4 & 33.3 & basic $^{T}$ & 66.6 & $\operatorname{basic}^{\mathrm{F}}$, fashion ${ }^{\mathrm{F}}$ & basic $^{\mathrm{T}^{+}}$ \\
\hline Scenario 5 & 50.0 & basic $^{T}$ & 50.0 & basic $^{\mathrm{F}}$, fashion ${ }^{\mathrm{F}}$ & basic $^{\mathrm{T}^{+}}$ \\
\hline Scenario 6 & 66.6 & basic $^{\mathrm{T}}$ & 33.3 & basic $^{\mathrm{F}}$, fashion ${ }^{\mathrm{F}}$ & basic $^{\mathrm{T}^{+}}$ \\
\hline
\end{tabular}


In each scenario, manufacturer $\mathrm{T}$ offers only a basic product basic ${ }^{\mathrm{T}}$, while manufacturer $\mathrm{F}$ offers a basic product basic ${ }^{\mathrm{F}}$ and a fashion product fashion ${ }^{\mathrm{F}}$. The market shares of the two manufacturers differ in each scenario, as does the supply chain strategy adopted by the new market entrant. In Scenarios 1-3, a new competitor $\mathrm{F}^{+}$moves into the market, offering a basic product basic $\mathrm{F}^{+}$and a fashion product fashion $\mathrm{F}^{+}$-following a typical fast fashion strategy. In contrast, in Scenarios 4-6, the new competitor $\mathrm{T}^{+}$follows a traditional supply chain strategy and offers only a basic product basic $\mathrm{T}^{\mathrm{T}^{+}}$.

In addition, we test the effectiveness of four management measures that are applied by the new competitor. In practice, these measures might be combined. Our simulation can simulate any portfolio of measures, but we test them separately for the sake of analyzing the effect of each measure. In Measure 1, the price of the new competitor's products is reduced by $10 \%$, while all other parameters remain unchanged. In Measure 2, the quality is increased by $10 \%$, while in Measure 3 the new products have a higher trendiness factor-for example, because of better market research in advance. Market entry in Measure 4 is accompanied by a comprehensive advertising campaign regarding the new products - the campaign reaches $20 \%$ of the consumers, who are informed several times about the outstanding quality of the new competitor's products.

\subsection{Results}

The model was implemented in AnyLogic (www.anylogic.com), a widely used Java-based software program for agent-based simulation. We performed 100 simulation runs for the application of each measure to each scenario over a simulation horizon of five years using different seeds (a robustness analysis indicates that 100 replications with different random seeds suffice for obtaining stable results; for an example see "Appendix A"). The outcome was averaged over all runs. Each single simulation run requires a runtime of about three seconds; hence, each complete simulation of all six scenarios, five measures, and 100 replications requires a total of $150 \mathrm{~min}$ of runtime on a standard notebook system $(2.3 \mathrm{GHz}, 8 \mathrm{~GB}$ RAM, SSD).

Figure 3 shows the market shares for the four or five products available on the market for each combination of scenario and potential management measure (note that the number of products depends on the type of the new competitor, i.e., $\mathrm{T}^{+}$vs. $\mathrm{F}^{+}$). The new competitor's market shares differ under the two alternative supply chain strategies; for a formal test with respect to the difference's statistical significance, see "Appendix B".

For this first analysis, we have assumed that in all scenarios, products are available in the demanded quantity - here, supply is exactly in line with demand. The simulation results suggest that reducing the price by $10 \%$ (Measure 1) has nearly no effect on the market share in any scenario because our consumer agents are rather price-insensitive. Furthermore, a $10 \%$ increase in the quality of a product (Measure 2) has a considerably more positive effect on the market share captured by the new product than a $10 \%$ increase in the trendiness factor (Measure 3). The reason for this is that the consumers are parameterized-based on our (conjoint) study—as seeking high quality over high fashion.

By contrasting the fast fashion and the traditional supply chain strategies-for example, by comparing the corresponding Scenarios 1 and 4-it is noteworthy that the new basic product captures market shares from not only the existing basic ${ }^{\mathrm{T}}$ and $\operatorname{basic}^{\mathrm{F}}$ products but also the fashion ${ }^{\mathrm{F}}$ product due to individual consumer behavior and product characteristics. It should be remembered that the market characteristics in Scenarios 1 and 4 are identical; these two scenarios only differ in the strategy implemented by the new competitor: the new market 


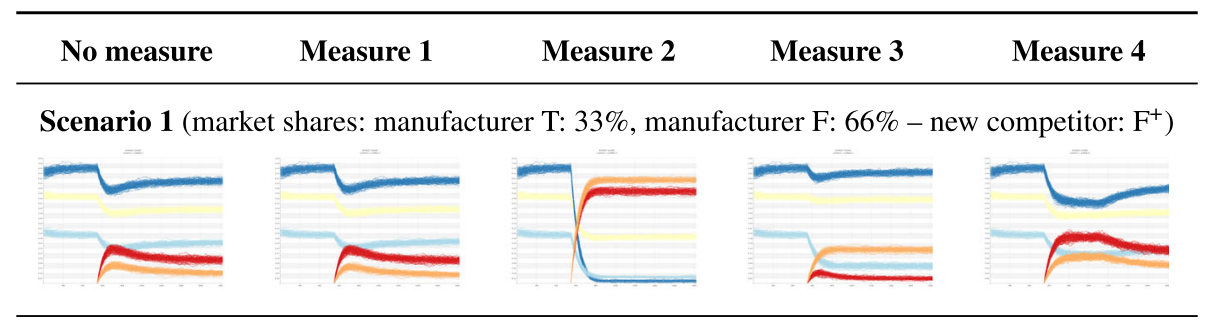

Scenario 2 (market shares: manufacturer T: 50\%, manufacturer F: 50\% - new competitor: $\mathrm{F}^{+}$)
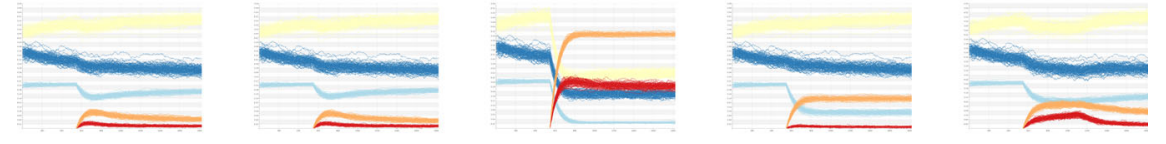

Scenario 3 (market shares: manufacturer T: $66 \%$, manufacturer F: 33\% - new competitor: $\mathrm{F}^{+}$)
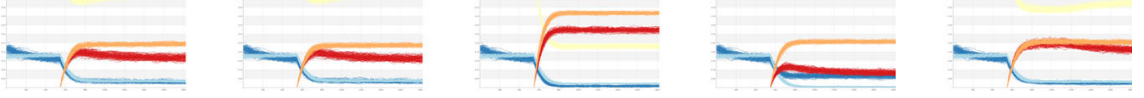

Scenario 4 (market shares: manufacturer T: 33\%, manufacturer F: 66\% - new competitor: $\mathrm{T}^{+}$)
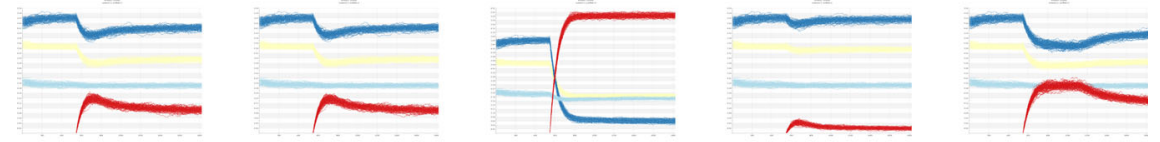

Scenario 5 (market shares: manufacturer T: 50\%, manufacturer F: 50\% - new competitor: $\mathrm{T}^{+}$)
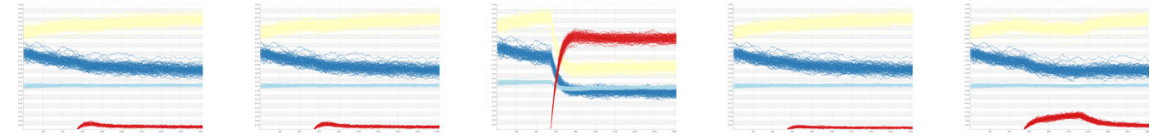

Scenario 6 (market shares: manufacturer T: $66 \%$, manufacturer F: $33 \%$ - new competitor: $\mathrm{T}^{+}$)
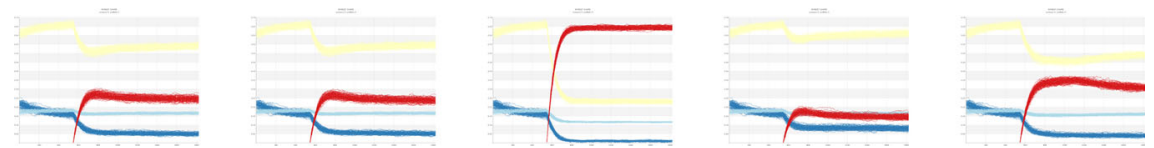

basic $^{\mathrm{T}}$

basic $^{\mathrm{F}}$

fashion $^{\mathrm{F}}$

basic $^{\mathrm{T}+/ \mathrm{F}^{+}}$

fashion $^{\mathrm{F}+}$

Fig. 3 Strategies and measures (market shares)

actor follows a fast fashion strategy in Scenario 1 and a traditional supply chain strategy in Scenario 4. The same applies to Scenarios 2 versus 5 and Scenarios 3 versus 6, respectively.

Overall, the new competitor's total market share is lower if the newcomer enters the market as a traditional manufacturer rather than as a fast fashion manufacturer. This finding suggests that in our fictitious apparel market, a fast fashion supply chain strategy might be the better option for a new competitor entering the market. 


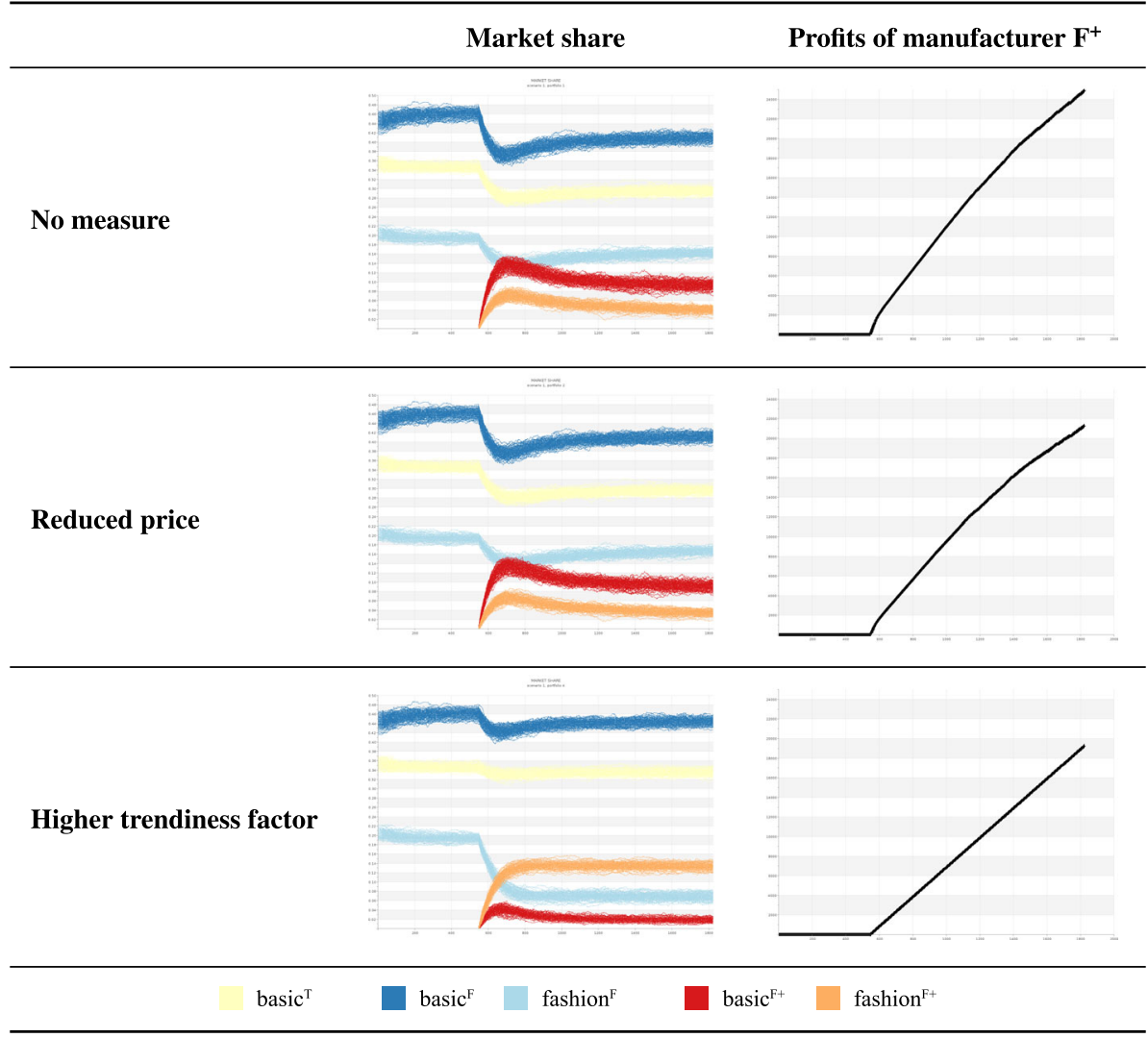

Fig. 4 Comparing market shares and profits in Scenario 1

We also analyzed the results with respect to profits. Figure 4 provides an example: it depicts the results for one specific scenario-Scenario 1-and compares the outcomes when no additional measure is applied against either lowering the price or increasing the trendiness factor. With respect to market share, increasing the trendiness factor by $10 \%$ seems to be the best option, as it results in a surplus of $14.2 \%$ in market share for the products basic $\mathrm{F}^{+}$and fashion $\mathrm{F}^{+}$of the new fast fashion manufacturer in Scenario 1. However, the profits decrease by $22.7 \%$ compared to the situation wherein the trendiness factor is not raised. This is owing to cannibalization of the new manufacturer's own high-margin basic $\mathrm{F}^{+}$product by the lowermargin fashion ${ }^{\mathrm{F}^{+}}$product. The alternative measure of reducing the product price by $10 \%$ does not substantially change the market share $(13.3 \%$ vs. $12.5 \%)$, given the price-insensitivity of consumers, but it reduces profits by nearly $14.5 \%$. With respect to profits, the results confirm that a fast fashion supply chain strategy in this scenario might still be the best option-this results in higher profits for the new competitor for all strategy measures. 
Table 4 Relative reduction of profits for the new competitor due to unsold products

\begin{tabular}{llllll}
\hline & Basis & Measure 1 $(\%)$ & Measure 2 $(\%)$ & Measure 3 $(\%)$ & Measure 4 $(\%)$ \\
\hline Scenario 1 & 51.7 & 53.8 & 22.3 & 96.7 & 24.0 \\
Scenario 2 & $>100$ & $>100$ & 26.2 & 99.7 & $>100$ \\
Scenario 3 & 20.7 & 20.7 & 21.9 & 36.5 & 19.7 \\
Scenario 4 & 40.3 & 43.0 & 0.1 & $>100$ & 14.0 \\
Scenario 5 & $>100$ & $>100$ & 3.4 & $>100$ & $>100$ \\
Scenario 6 & 0.6 & 0.6 & 0.0 & 10.4 & 0.3 \\
\hline
\end{tabular}

fashion $^{\mathrm{F}^{+}}$

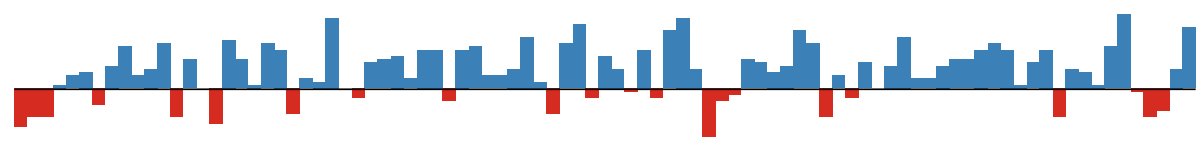

Fig. 5 Stocks and shortages of product fashion ${ }^{\mathrm{F}+}$ in Scenario 3 with Measure 1

Our simulation results are impacted by the definition of profits. For example, if the production costs of unsold products at the end of each selling season are included, the profits of the new competitor decrease and may even become negative (i.e., reduction of profits is more than $100 \%$ ), see Table 4.

Our agent-based simulation approach also allows us to identify lost sales when consumers switch to another product because their first-choice product is out of stock, resulting in loss of market share and consequently loss of profits for the manufacturer. For example, a detailed analysis of product fashion $\mathrm{F}^{+}$in Scenario 3 with application of Measure 1 shows that there are periods with stock-outs (see Fig. 5).

Regarding profits, these results are only examples intended to demonstrate our agent-based model. Quite obviously, outcomes in practice depend largely on production volumes. In our application case, all manufacturers expect a growing market and, as a rule of thumb, restock their inventory by $+15 \%$ of the number of products sold in the previous season.

\section{Conclusions}

In this paper, we introduced an agent-based model of an apparel market that takes into account relevant stakeholders (i.e., manufacturers and consumers) as well as their actions and interactions. The corresponding simulation tool can be used to study the benefit of a fast fashion supply chain strategy over a traditional strategy (and vice versa). Furthermore, we demonstrated the strengths of the simulation approach in comparison with the analytic approach by Cachon and Swinney (2011) in a more realistic market setting that also allows for heterogeneity of consumers along with word-of-mouth communication. Results suggest that accounting for these market characteristics indeed makes a difference. Finally, we analyzed the effectiveness of the two supply chain strategies in combination with four management measures, thus, exemplifying possible support for decision-makers in exploring what-if questions to aid the identification of the most convenient individual strategy. 
The model and its application are still subject to limitations and remaining challenges. First, we have modeled a fictitious environment, so it is impossible to derive managerial implications for a specific apparel market from this sample application. However, our application case shows that it could be worthwhile to collect empirical data from a real market and run the simulations with a corresponding parameterization. Next, the consumer side of our market model could be extended to investigate further research questions. Such extensions may concern consumer purchasing behavior (e.g., modeling shopping as a favorite pastime for some consumers that might result in spontaneous purchases), consumer communication behavior (e.g., the type of topics on which peers exchange their attitudes and how often they choose which type of topic), the availability of diverse points of sale with various characteristics and their efforts to attract consumers, and additional marketing measures (e.g., running campaigns through social media influencers), all of which constitute promising starting points for future research. Modeling the effects of stock-outs beyond lost sales is another example for an extension of our market model: corresponding effects might be positive because the product is perceived as rare and consumers are prompted to immediately purchase an item they are interested in without postponing the purchase in order to look for a similar items in other stores, or these effects might be negative because stock-outs damage a store's (brand's) reputation. Then, it might be interesting to analyze the effects of combining marketing measures into strategy portfolios to identify the potential strengthening or cannibalization effects of the various measures. The procedure for calculating profits could be refined to consider certain realities - for example, a gain in quality is related to higher production costs or a "trendier" product is linked with cost-intensive market research. Finally, the model could be extended to consider several competitors with a more refined strategy and perhaps even with the ability to fine-tune their strategies with respect to market developments (e.g., responding to unsold items or stock-outs of items). In this context, also brands as well as brand image or brand reputation could be added to the simulation.

Overall, this work represents the first agent-based simulation of an apparel market. It demonstrates the ability of such an approach to capture the emergent behavior in this market, thereby showing the opportunity for additional work in this field.

Acknowledgements Open Access funding provided by Projekt DEAL.

Open Access This article is licensed under a Creative Commons Attribution 4.0 International License, which permits use, sharing, adaptation, distribution and reproduction in any medium or format, as long as you give appropriate credit to the original author(s) and the source, provide a link to the Creative Commons licence, and indicate if changes were made. The images or other third party material in this article are included in the article's Creative Commons licence, unless indicated otherwise in a credit line to the material. If material is not included in the article's Creative Commons licence and your intended use is not permitted by statutory regulation or exceeds the permitted use, you will need to obtain permission directly from the copyright holder. To view a copy of this licence, visit http://creativecommons.org/licenses/by/4.0/.

\section{A Testing for sufficient number of simulation runs}

Exemplary comparison of two sets of runs (with different seeds) for Scenario 1 with no measures applied. 


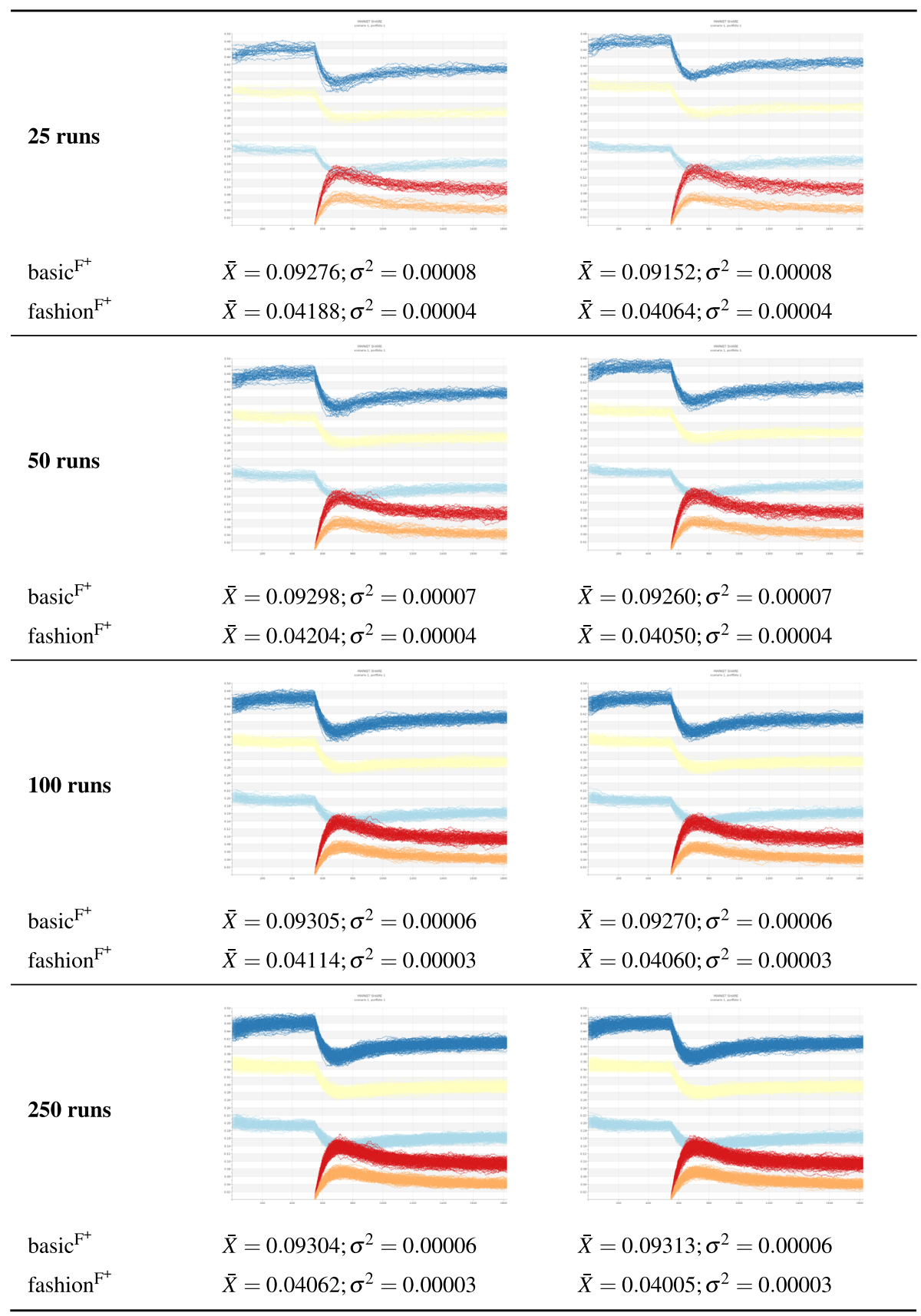




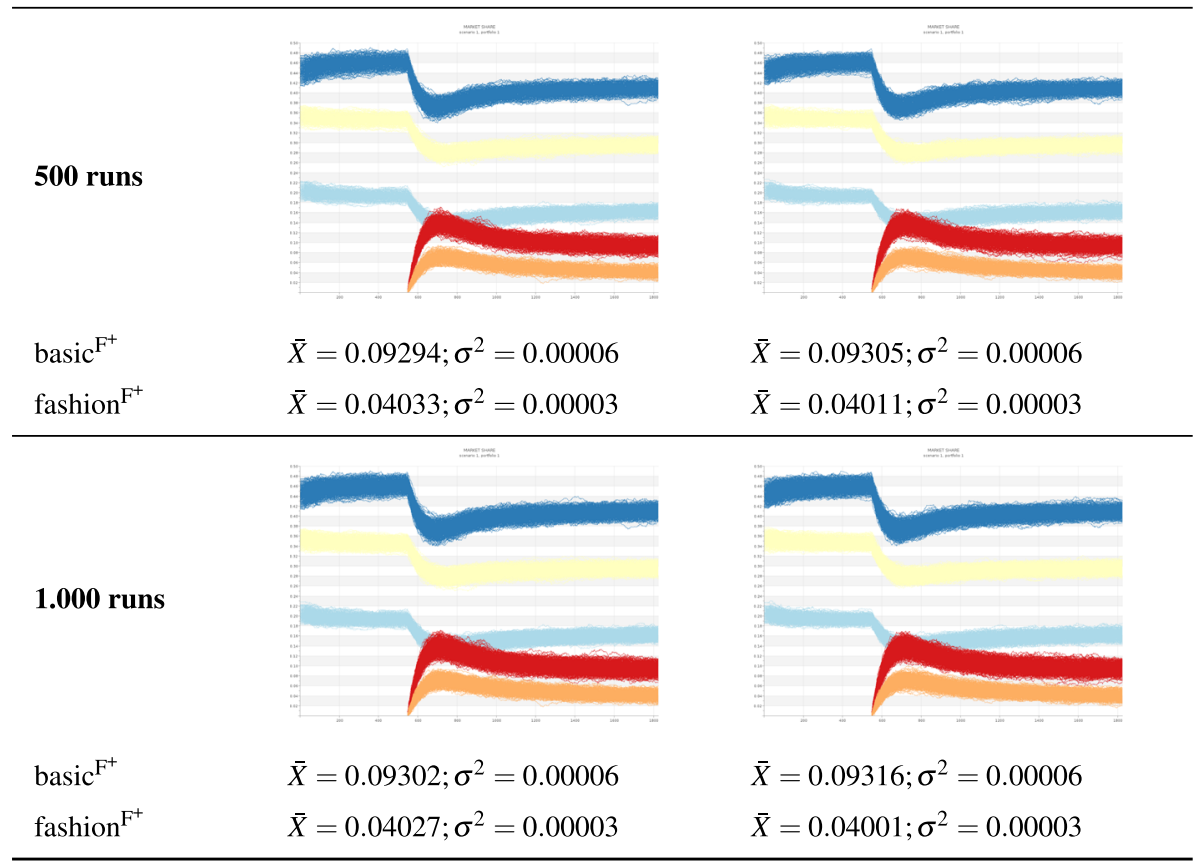

\section{B Testing for significant differences among the outcomes of alternative strategies}

For testing whether the differences in the market shares of the new competitor are significant in case of application of the two alternative supply chain strategies, we first compared the combined market shares from products basic $\mathrm{F}^{+}$and fashion $\mathrm{F}^{+}$in Scenario 1 with the market share of the product basic $\mathrm{T}^{+}$in Scenario 4. Next, we proceeded in an analogous way for Scenarios 2 versus 5 and Scenarios 3 versus 6, respectively.

The corresponding $t$-values are listed in the table below. All the differences are significant for a $p$-level threshold of 0.01 . Moreover, we checked for first-order stochastic dominance of the most successful strategy (for an overview of stochastic dominance, see Levy 1992) and found stochastic dominance in all instances but one. The exception occurs in case of the application of Measure 1 in Scenarios 1 and 4-but even in this instance, the overlap of the simulation results is very small.

\begin{tabular}{llllll}
\hline Scenarios & No measure & Measure 1 & Measure 2 & Measure 3 & Measure 4 \\
\hline 1 versus 4 & $36.727^{*}$ & $31.270^{*}$ & $205.901^{*}$ & $173.906^{*}$ & $55.979^{*}$ \\
2 versus 5 & $67.562^{*}$ & $64.321^{*}$ & $133.608^{*}$ & $197.805^{*}$ & $93.171^{*}$ \\
3 versus 6 & $106.069^{*}$ & $106.423^{*}$ & $89.793^{*}$ & $150.205^{*}$ & $126.131^{*}$
\end{tabular}

\footnotetext{
*Significant differences $(p=0.01, d f=198)$
} 


\section{References}

Aral, S., \& Walker, D. (2014). Tie strength, embeddedness, and social influence: A large-scale networked experiment. Management Science, 60(6), 1352-1370.

Backs, S., Jahnke, H., Lüpke, L., Stücken, M., \& Stummer, C. (2020) Supply chain strategies of the apparel industry in research: A literature review. Working paper. SSRN: https://ssrn.com/abstract=3558419.

Barabási, A., \& Albert, R. (1999). Emergence of scaling in random networks. Science, 286(5439), 509-512.

Barabási, A., \& Bonabeau, E. (2003). Scale-free networks. Scientific American, 288(5), 50-59.

Barnes, L., \& Lea-Greenwood, G. (2006). Fast fashioning the supply chain: Shaping the research agenda. Journal of Fashion Marketing and Management, 10(3), 259-271.

Butcher, K., Sparks, B., \& O'Callaghan, F. (2002). Effect of social influence on repurchase intentions. Journal of Services Marketing, 16(6), 503-514.

Byun, S. E., \& Sternquist, B. (2008). The antecedents of in-store hoarding: Measurement and application in the fast fashion retail environment. International Review of Retail, Distribution and Consumer Research, 18(2), 133-147.

Cachon, G. P., \& Swinney, R. (2011). The value of fast fashion: Quick response, enhanced design, and strategic consumer behavior. Management Science, 57(4), 778-795.

Caro, F., \& Gallien, J. (2007). Dynamic assortment with demand learning for seasonal consumer goods. Management Science, 53(2), 276-292.

Caro, F., \& Gallien, J. (2010). Inventory management of a fast-fashion retail network. Operations Research, $58(2), 257-273$.

Caro, F., \& Martínez-de-Albéniz, V. (2015). Fast fashion: Business model overview and research opportunities. In N. Agrawal \& S. A. Smith (Eds.), Retail supply chain management (pp. 237-264). New York: Springer.

Choi, T. M., Liu, N., Liu, S. C., Mak, J., \& To, Y. T. (2010). Fast fashion brand extensions: An empirical study of consumer preferences. Journal of Brand Management, 17(7), 472-487.

Christopher, M., Lowson, R., \& Peck, H. (2004). Creating agile supply chains in the fashion industry. International Journal of Retail \& Distribution Management, 32(8), 367-376.

Cialdini, R. B., \& Goldstein, N. J. (2004). Social influence: Compliance and conformity. Annual Review of Psychology, 55, 591-621.

Ferdows, K., Lewis, M. A., \& Machuca, J. A. D. (2004). Rapid-fire fulfillment. Harvard Business Review, 82(11), 104-117.

Delre, S. A., Jager, W., Bijmolt, T. H., \& Janssen, M. A. (2007). Targeting and timing promotional activities: An agent-based model for the takeoff of new products. Journal of Business Research, 60(8), 826-835.

Delre, S. A., Jager, W., Bijmolt, T. H., \& Janssen, M. A. (2010). Will it spread or not? The effects of social influences and network topology on innovation diffusion. Journal of Product Innovation Management, 27(2), 267-282.

Hayllar, W., Sorensen, D., \& Carall-Green, S. (2019) A generation without borders: Embracing generation Z. OC\&C Strategy Consultants. Retrieved February 06, 2020 from https://www.occstrategy.com/media/ 1806/a-generation-without-borders.pdf.

Joy, A., Sherry, J. F, Jr., Venkatesh, A., Wang, J., \& Chan, R. (2012). Fast fashion, sustainability, and the ethical appeal of luxury brands. Fashion Theory, 16(3), 273-295.

Kiesling, E., Günther, M., Stummer, C., \& Wakolbinger, L. M. (2012). Agent-based simulation of innovation diffusion: A review. Central European Journal of Operations Research, 20(2), 183-230.

Latané, B. (1981). The psychology of social impact. American Psychologist, 36(4), 343-356.

Levy, H. (1992). Stochastic dominance and expected utility: Survey and analysis. Management Science, 38(4), $555-593$.

Li, J., Choi, T. M., \& Cheng, T. C. E. (2014a). Mean variance analysis of fast fashion supply chains with returns policy. IEEE Transactions on Systems, Man, and Cybernetics: Systems, 44(4), 422-434.

Li, Y., Zhao, X., Shi, D., \& Li, X. (2014b). Governance of sustainable supply chains in the fast fashion industry. European Management Journal, 32(5), 823-836.

MacCarthy, B. L., \& Jayarathne, P. G. S. A. (2010). Fast fashion: Achieving global quick response (GQR) in the internationally dispersed clothing industry. In T. C. E. Cheng \& T.-M. Choi (Eds.), Innovative quick response programs in logistics and supply chain management (pp. 37-60). New York: Springer.

Morgan, L. R., \& Birtwistle, G. (2009). An investigation of young fashion consumers' disposal habits. International Journal of Consumer Studies, 33(2), 190-198.

Negahban, A., \& Jeffrey, S. S. (2018). A joint analysis of production and seeding strategies for new products: An agent-based simulation approach. Annals of Operations Research, 268(1-2), 41-62.

Rand, W., \& Rust, R. T. (2011). Agent-based modeling in marketing: Guidelines for rigor. International Journal of Research in Marketing, 28(3), 181-193. 
Rand, W., Rust, R. T., \& Kim, M. (2018). Complex systems: Marketing's new frontier. AMS Review, 8(3-4), 111-127.

Risselada, H., Verhoef, P. C., \& Bijmolt, T. H. (2014). Dynamic effects of social influence and direct marketing on the adoption of high-technology products. Journal of Marketing, 78(2), 52-68.

Runfola, A., \& Guercini, S. (2013). Fast fashion companies coping with internationalization: Driving the change or changing the model? Journal of Fashion Marketing and Management, 17(2), 190-205.

Sonderegger-Wakolbinger, L. M., \& Stummer, C. (2015). An agent-based simulation of customer multi-channel choice behavior. Central European Journal of Operations Research, 23(2), 459-477.

Squazzoni, F., Jager, W., \& Edmonds, B. (2014). Social simulation in the social science: A brief overview. Social Science Computer Review, 32(3), 279-297.

Stummer, C., Kiesling, E., Günther, M., \& Vetschera, R. (2015). Innovation diffusion of repeat purchase products in a competitive market: An agent-based simulation approach. European Journal of Operational Research, 245(1), 157-167.

Tang, L., Jin, Z., Qin, X., \& Jing, K. (2019). Supply chain scheduling in a collaborative manufacturing mode: Model construction and algorithm design. Annals of Operations Research, 275(2), 685-714.

Turker, D., \& Altuntas, C. (2014). Sustainable supply chain management in the fast fashion industry: An analysis of corporate reports. European Management Journal, 32(5), 837-849.

Wang, K., Gou, Q., Yang, L., \& Shan, S. (2013). Coordination of a fast fashion supply chain with profitloss sharing contract. In T.-M. Choi (Ed.), Fast fashion systems: Theories and applications (pp. 77-92). London: CRC Press.

Publisher's Note Springer Nature remains neutral with regard to jurisdictional claims in published maps and institutional affiliations. 